\title{
Salt adaptability in a halophytic soybean (Glycine soja) involves photosystems coordination
}

Kun Yan ${ }^{1 *}$, Wenjun He${ }^{1}$, Lanxing Bian ${ }^{1,2}$, Zishan Zhang ${ }^{3}$, Xiaoli Tang ${ }^{4}$, Mengxin An ${ }^{4}$, Lixia Li ${ }^{2}$ and Guangxuan $\operatorname{Han}^{1^{*}}$

\begin{abstract}
Background: Glycine soja is a halophytic soybean native to saline soil in Yellow River Delta, China. Photosystem I (PSI) performance and the interaction between photosystem II (PSII) and PSI remain unclear in Glycine soja under salt stress. This study aimed to explore salt adaptability in Glycine soja in terms of photosystems coordination.

Results: Potted Glycine soja was exposed to $300 \mathrm{mM} \mathrm{NaCl}$ for 9 days with a cultivated soybean, Glycine max, as control. Under salt stress, the maximal photochemical efficiency of PSII (FV/Fm) and PSI ( $\left.\triangle \mathrm{MR} / \mathrm{MR}_{0}\right)$ were significantly decreased with the loss of PSI and PSII reaction center proteins in Glycine max, and greater PSI vulnerability was suggested by earlier decrease in $\triangle \mathrm{MR} / \mathrm{MR}_{0}$ than $\mathrm{Fv} / \mathrm{Fm}$ and depressed PSI oxidation in modulated $820 \mathrm{~nm}$ reflection transients. Inversely, PSI stability was defined in Glycine soja, as $\triangle M R / M R_{0}$ and PSI reaction center protein abundance were not affected by salt stress. Consistently, chloroplast ultrastructure and leaf lipid peroxidation were not affected in Glycine soja under salt stress. Inhibition on electron flow at PSII acceptor side helped protect PSI by restricting electron flow to PSI and seemed as a positive response in Glycine soja due to its rapid recovery after salt stress. Reciprocally, PSI stability aided in preventing PSII photoinhibition, as the simulated feedback inhibition by PSI inactivation induced great decrease in Fv/Fm under salt stress. In contrast, PSI inactivation elevated PSII excitation pressure through inhibition on PSII acceptor side and accelerated PSII photoinhibition in Glycine max, according to the positive and negative correlation of $\triangle M R / M R_{0}$ with efficiency that an electron moves beyond primary quinone and PSII excitation pressure respectively.
\end{abstract}

Conclusion: Therefore, photosystems coordination depending on PSI stability and rapid response of PSII acceptor side contributed to defending salt-induced oxidative stress on photosynthetic apparatus in Glycine soja. Photosystems interaction should be considered as one of the salt adaptable mechanisms in this halophytic soybean.

Keywords: Chlorophyll fluorescence, Chloroplast ultrastructure, Modulated $820 \mathrm{~nm}$ reflection, Oxidative stress, Photoinhibition

\footnotetext{
* Correspondence: kyan@yic.ac.cn; gxhan@yic.ac.cn

'CAS Key Laboratory of Coastal Environmental Processes and Ecological Remediation, Yantai Institute of Coastal Zone Research (YIC), Chinese Academy of Sciences(CAS), Shandong Key Laboratory of Coastal Environmental Processes, YICCAS, Yantai, Shandong 264003, P. R. China Full list of author information is available at the end of the article
}

(c) The Author(s). 2020 Open Access This article is licensed under a Creative Commons Attribution 4.0 International License, which permits use, sharing, adaptation, distribution and reproduction in any medium or format, as long as you give appropriate credit to the original author(s) and the source, provide a link to the Creative Commons licence, and indicate if changes were made. The images or other third party material in this article are included in the article's Creative Commons licence, unless indicated otherwise in a credit line to the material. If material is not included in the article's Creative Commons licence and your intended use is not permitted by statutory regulation or exceeds the permitted use, you will need to obtain permission directly from the copyright holder. To view a copy of this licence, visit http://creativecommons.org/licenses/by/4.0/. The Creative Commons Public Domain Dedication waiver (http://creativecommons.org/publicdomain/zero/1.0/) applies to the data made available in this article, unless otherwise stated in a credit line to the data. 


\section{Background}

It is a great challenge to supply increasing population with enough food in future under the background of worldwide land degradation [1,2]. Soil salinization is a major kind of land degradation and poses a serious threat to sustainable agricultural production. Irrigated farmland usually confronts secondary salinization because of unreasonable irrigation and fertilization, whereas large areas of saline land due to primary salinization are distributed in coastal zone and inland arid region [1]. In contrast to single soil improvement, biosaline agriculture has been proposed as an environmental friendly approach for managing saline land [3-5]. Halophytic crops are important germplasm resource, and besides direct planting in saline land, they also can be used for breeding new genotypes with salt tolerance by traditional hybridization or gene transformation. However, it is better to ascertain physiological mechanisms for adapting to saline stress in halophytes beforehand.

Salt stress disturbs plant metabolisms and inhibits plant growth by inducing osmotic stress and ionic toxicity, and as a salt-induced secondary stress, oxidative damage on biological macromolecules often arises [6-8]. Correspondingly, plants have evolved some defensive mechanisms such as root $\mathrm{Na}^{+}$exclusion, osmolyte synthesis and antioxidant induction. These defensive mechanisms generally work more effectively in halophytes, and additionally, some special defensive behaviors exist in halophytes for their survival in saline land, such as salt secretion by glands and salt accumulation in vacuoles as osmolytes [8-12]. Plant survival and growth largely depend on photosynthesis. Photosynthesis is very sensitive to salt stress, and photosynthetic capacity seems to be a feasible criterion for differentiating plant salt tolerance [13-18]. In general, stomatal limitation on photosynthesis initially occurs due to salt-induced osmotic stress, and the inhibition on dark enzymatic processes can further reduce $\mathrm{CO}_{2}$ fixation $[17,19,20]$. As a consequence, excitation pressure in chloroplast may be elevated to induce photosystems photoinhibition with excess ROS production [21, 22]. At present, most studies focus on salt-induced photosystem II (PSII) photoinhibition, and halophytes generally have higher PSII photochemical capacity and $\mathrm{CO}_{2}$ assimilation rate than the glycophytic relatives under salt stress [14, 23, 24]. However, it remains unclear whether PSII components involving reaction center, donor and acceptor electron carriers have the uniform response in halophyte under salt stress.

Up to now, very limited attention has been paid to photosystem I (PSI) under salt stress, let alone the interaction between PSII and PSI [16]. In our recent studies, PSI was proved to be a crucial photoinhibition site in some glycophytic crops under salt stress [18, 25, 26].
Unlike PSII, it is hard to repair damaged PSI [22]. PSI photoinhibition can intensify PSII excitation pressure through feedback inhibition on electron transport and aggravate PSII photoinhibition [27, 28]. Accordingly, PSI inactivation has been found in susceptible plant species or cultivars with weak adaptability to abiotic stresses [18, 25, 28]. In contrast, PSII photoinhibition which restricts electron donation to PSI can help to prevent PSI photoinhibition by reducing ROS generation through Mehler reaction at PSI acceptor side [29-33]. Therefore, PSII and PSI coordination plays an important role in protecting the whole photosynthetic apparatus. In addition to great ability to defense ionic toxicity and osmotic stress, halophytes can effectively dissipate excitation energy in chloroplast and scavenge ROS for protecting PSII from oxidative damage, and PSII photoinhbition is rarely reported in halophytes under salt stress [14, 23, 24, 34]. Notably, PSII stability can elevate the possibility of PSI oxidative injury in halophytes particularly under longterm severe salt stress with tremendous decrease in $\mathrm{CO}_{2}$ assimilation. Up to now, PSII and PSI coordination has not been reported in halophytes upon salt stress, and it remains unknown whether halophytes can protect PSI against photoinhibition by the flexible response of PSII.

Wild soybeans are precious germplasm resources for improving environmental adaptability in cultivated soybean. Glycine cyrtoloba is a wild soybean species native to saline soil in Australian beach, and a series of studies have demonstrated its high salt tolerance in terms of inhibiting $\mathrm{Na}^{+}$accumulation, photosynthetic activity, antioxidant activity, cyclic electron flow around PSI and excitation energy dissipation [23, 34-36]. In China, a halophytic soybean, Glycine soja, grows in coastal saline land in Yellow River Delta, and similar to Glycine cyrtoloba, Glycine soja also can effectively retard toxic ions accumulation and maintain high photosynthetic activity under salt stress [24, 37, 38]. In a recent study, we systematically illustrated salt tolerance in Glycine soja from the aspects of root ions flux, antioxidant system, osmotic regulation and photosynthesis [14]. Nonetheless, photosynthetic analysis was mainly concentrated on gas exchange characterization in these halophytic soybeans upon salt stress, and PSII salt tolerance was only defined by no obvious change in the maximal photochemical efficiency of PSII (Fv/Fm). Fv/Fm cannot reflect heterogeneous behaviors of PSII components [39], and PSI performance and the coordination between PSII and PSI remain unclear in the halophytic soybean under salt stress. In this study, we attached importance to photosystem performance and photosynthetic electron transport, and aimed to deeply reveal salt adaptability in Glycine soja by elucidating photosystems coordination. This study can provide an insight to crop salt tolerance and may assist in soybean germplasm improvement. 


\section{Results}

Gas exchange, electron transport rate and PSIl excitation pressure

Photosynthetic rate $(\mathrm{Pn})$, stomatal conductance $\left(\mathrm{g}_{\mathrm{s}}\right)$ and PSII electron transport rate (ETR) were significantly decreased in the leaves of Glycine soja and Glycine max under salt stress, and greater decrease was noted in Glycine $\max$ (Fig. 1a, b, d). Under salt stress, PSII excitation pressure (1-qP) was significantly increased by $35.6 \%$ in Glycine $\max$ at day 3, and the increase reached $72.5 \%$ at day 9 (Fig. 1c). After 6 days of salt stress, significant increase in 1-qP was observed in Glycine soja, and the increase was up to $50.3 \%$ at day 9 (Fig. 1c).

Prompt chlorophyll $a$ fluorescence (PF), modulated 820 $\mathrm{nm}$ reflection transients (MR) and delayed chlorophyll $a$ fluorescence (DF)

If the re-oxidation of primary quinone $\left(\mathrm{Q}_{\mathrm{A}}\right)$ and plastoquinone (PQ) are inhibited, J and I steps will appear [40, 41]. After 3 days of salt stress, J and I steps were obviously elevated in Glycine $\max$ (Fig. 2a), and the elevation of J and I steps became greater upon salt stress for 9 days (Fig. 2b), suggesting that PQ re-oxidation and electron transfer at PSII side beyond $\mathrm{Q}_{\mathrm{A}}$ were inhibited. $\mathrm{K}$ step usually arises around $300 \mu$ s due to the injury on OEC at PSII donor side $[42,43]$. After 3 days of salt stress, PSII donor side was impaired in Glycine max according to the appearance of K step (Fig. 2a). Comparatively, salt stress induced smaller elevation of $J$ and I steps with no change in K step in Glycine soja (Fig. 2a, b).

$M R$ signals are presented by $M R / M R_{0}$ ratio, where $\mathrm{MR}_{0}$ is the value at onset of actinic illumination (at $0.7 \mathrm{~ms}$ ). PSI oxidation was initiated with the decrease in $M R / M R_{0}$ from $M R_{0}$ to the minimal value (MRmin) in MR transient, and subsequently, the increase of $M R / M R_{0}$ to the maximal level (MRmax) indicates PSI re-reduction. MR transient remarkably changed with significantly decreased $M_{0}-M R m i n$ and MRmax-MRmin in Glycine max under salt stress (Fig. 2c, d), suggesting that both PSI oxidation and re-reduction were negatively affected. In contrast, PSI oxidation and re-reduction were not inhibited by

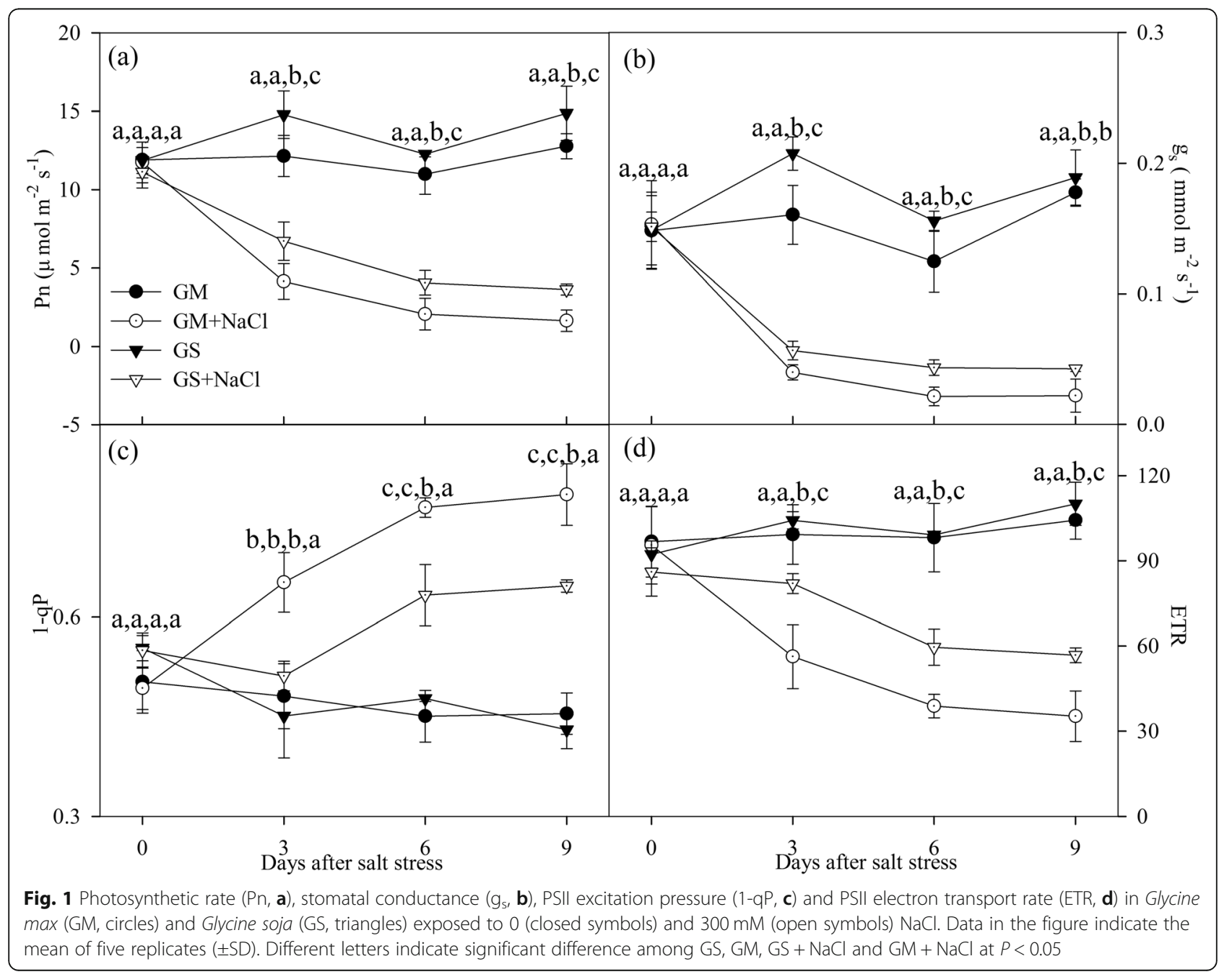



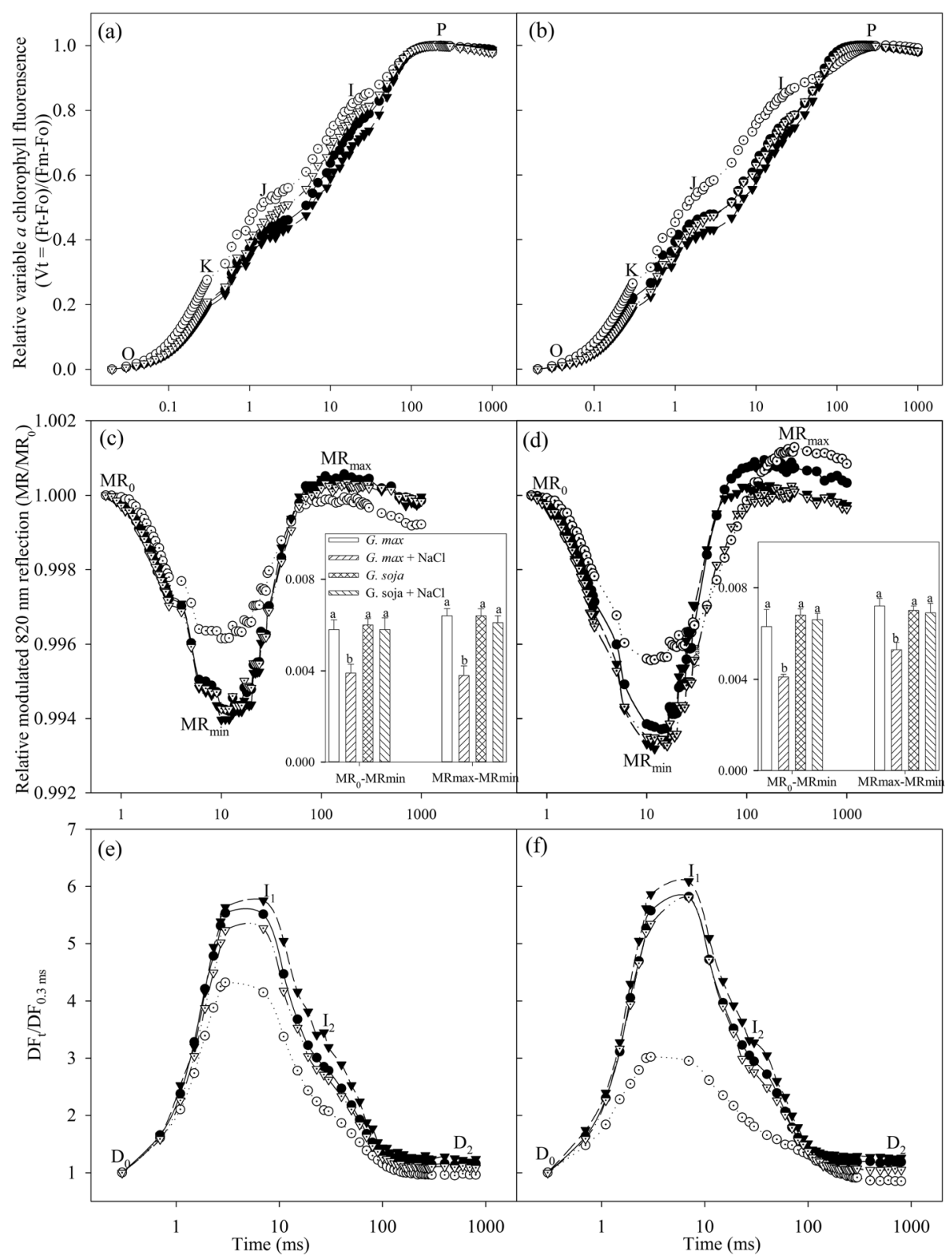

Fig. 2 Transients of prompt chlorophyll a fluorescence a, b, modulated $820 \mathrm{~nm}$ reflection $\mathbf{c}$, d, and delayed chlorophyll a fluorescence e, $\mathbf{f}$ in Glycine max (circles) and Glycine soja (triangles) exposed to 0 (closed symbols) and $300 \mathrm{mM}$ (open symbols) $\mathrm{NaCl}$ for 3 (left panels) and 9 (right panels) days. $\mathrm{O}, \mathrm{K}, \mathrm{J}, \mathrm{I}$ and $\mathrm{P}$ indicate the specific steps in chlorophyll a fluorescence transient. MR $\mathrm{R}_{0}$ is the value of modulated $820 \mathrm{~nm}$ reflection at the onset of red light illumination ( $0.7 \mathrm{~ms}$, the first reliable $M R$ measurement). MRo-MRmin and MRmax-MRmin were PSI oxidation and re-reduction amplitude, respectively. The data of MRo-MRmin and MRmax-MRmin indicate mean of five replicates $( \pm \mathrm{SD})$, and different letters on error bars indicate significant difference at $P<0.05$. Do, 11, 12, D2 indicate initial point, the first $(7 \mathrm{~ms})$ and second $(50 \mathrm{~ms})$ maximal peaks and minimum point in delayed chlorophyll a fluorescence curves. $D F_{0.3 \mathrm{~ms}}$ is the initial microsecond delayed fluorescence signal at $0.3 \mathrm{~ms}$. The signals were plotted on a logarithmic time scale, and each curve is the average of five replicates

salt stress in Glycine soja, as no obvious change was found in $\mathrm{MR}_{0}$-MRmin, MRmax-MRmin and $M R$ transient (Fig. 2c, d). Under salt stress, DF transient in G. $\max$ was prominently depressed with significant decrease in $I_{1}$ and $I_{2}$ peaks, but $I_{1}$ and $I_{2}$ peaks were slightly declined in Glycine soja (Fig. 2e, f).
Immunoblot analysis, PSII performance and the maximal photochemical capacity of PSI

After 9 days of salt stress, PSI reaction center protein (PsaA) and PSII reaction center protein (PsbA) abundance were obviously declined in Glycine max rather than Glycine soja (Fig. 3a, b). Salt stress significantly 


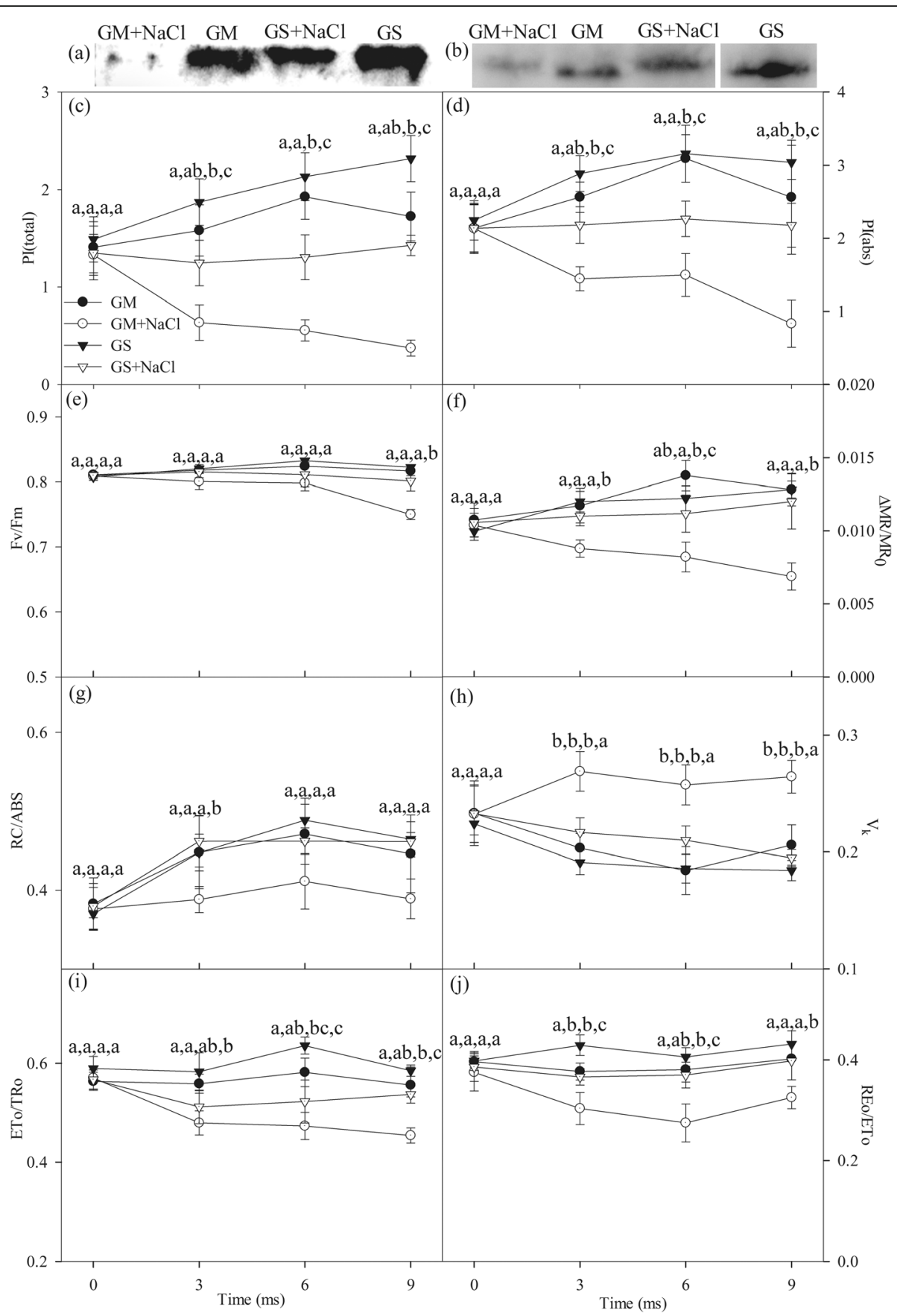

Fig. 3 Immunoblot analysis of reaction center proteins of PSI (PsaA, a) and PSII (PsbA, b) in the leaves of Glycine max (GM) and Glycine soja (GS) after 9 days of salt stress with $300 \mathrm{mM} \mathrm{NaCl}$. Total performance index ( $\left.\mathrm{Pl}_{\text {total, }} \mathbf{c}\right)$, PSIl performance index $\left(\mathrm{Pl}_{\mathrm{abs}}, \mathbf{d}\right)$, the maximal photochemical efficiency of PSII (Fv/Fm, e) and PSI $\left(\triangle M R / M R_{0}, \mathbf{f}\right)$, primary quinone reducing reaction centers per PSIl antenna chlorophyll (RC/ABS, $\mathbf{g}$ ), variable fluorescence intensity at $K$ step $\left(V_{k}, \mathbf{h}\right)$, probability that an electron moves beyond primary quinone $(E T o / T R o, i)$ and probability with which an electron from the intersystem electron carriers is transferred to reduce end electron acceptors at the PSI acceptor side (REo/ETo, $\mathbf{j}$ ) in the leaves of Glycine max (circles) and Glycine soja (triangles) exposed to 0 (closed symbols) and $300 \mathrm{mM}$ (open symbols) $\mathrm{NaCl}$. Data in the figure indicate the mean of five replicates $( \pm \mathrm{SD}$ ). Different letters indicate significant difference among $\mathrm{GS}, \mathrm{GM}, \mathrm{GS}+\mathrm{NaCl}$ and $\mathrm{GM}+\mathrm{NaCl}$ at $P<0.05$. The blot signals are cropped from the full-length blot images in Additional file 2: Figure S2 and Additional file 3: Figure S3

declined total performance index $\left(\mathrm{PI}_{\text {total }}\right)$ and PSII performance index $\left(\mathrm{PI}_{\mathrm{abs}}\right)$ in Glycine max and Glycine soja, and greater decrease was noted in Glycine max (Fig. 3c, d). Similarly, salt stress also induced greater decrease in probability with which an electron moves beyond $\mathrm{Q}_{\mathrm{A}}$ (ETo/TRo) and from the intersystem electron carriers to 
reduce PSI end electron acceptors (REo/ETo) in Glycine max than Glycine soja (Fig. 3i, j). Significant decrease in the maximal photochemical capacity of PSI $\left(\triangle M R / M_{0}\right)$ was noted in Glycine max rather than Glycine soja under salt stress, and salt-induced decrease in $\mathrm{Q}_{\mathrm{A}}$ reducing reaction centers per PSII antenna chlorophyll (RC/ABS) was also observed in Glycine max (Fig. 3f, g). In line with elevated $\mathrm{K}$ step (Fig. 2a, b), salt-induced significant increase in variable fluorescence intensity at $K$ step $\left(V_{k}\right)$ was also found in Glycine $\max$ (Fig. 3h). When salt stress was prolonged to 9 days, $\mathrm{Fv} / \mathrm{Fm}$ was significantly decreased in Glycine max, but the decrease in $\mathrm{Fv} / \mathrm{Fm}$ was not significant in Glycine soja (Fig. 3e).

\section{Recovery of photosystem performance}

One day after the cease of salt stress, $\mathrm{PI}_{\text {total }}, \mathrm{PI}_{\mathrm{abs}}, \mathrm{ETo} /$ TRo and REo/ETo in salt-treated Glycine soja rapidly recovered to the normal level in Glycine soja without salt treatment, implying the high salt tolerance of photosystems in Glycine soja (Table 1). Probably due to irreversible damage on photosystems, these parameters did not show recovery in Glycine max despite the cease of salt stress (Table 1).

\section{The coordination between PSI and PSII}

$\triangle \mathrm{MR} / \mathrm{MR}_{0}$ was significantly and positively correlated with ETo/TRo in Glycine max under salt stress, while significant and negative correlation was noted between $\triangle \mathrm{MR} / \mathrm{MR}_{0}$ and 1-qP (Fig. 4a, c). However, there was very low correlation of $\triangle \mathrm{MR} / \mathrm{MR}_{0}$ with ETo/TRo and 1-qP in Glycine soja (Fig. 4a, c). The application of DCMU, an inhibitor blocking the electron transport from $\mathrm{Q}_{\mathrm{A}}{ }^{-}$to $\mathrm{Q}_{\mathrm{B}}{ }^{-}$, caused much greater decrease in $\mathrm{Fv} / \mathrm{Fm}$ and ETo/ TRo in Glycine max and Glycine soja after 9 days of salt stress (Fig. 4b, d).

Table 1 Recovery of Total performance index $\left(\mathrm{PI}_{\text {total }}\right)$, PSII performance index $\left(\mathrm{Pl}_{\mathrm{abs}}\right)$, efficiency that an electron moves beyond primary quinone $(\mathrm{ETO} / \mathrm{TRO}$, ) and probability with which an electron from the intersystem electron carriers is transferred to reduce end electron acceptors at the PSI acceptor side (REo/ ETo) for one day in the leaves of Glycine soja (GS) and Glycine max (GM) after 9 days of salt stress with $300 \mathrm{mM} \mathrm{NaCl}$. Data in the table indicate the mean of five replicates $( \pm S D)$. Within each row, means followed by the same letters are not significantly different between salt treatment and control at $P<0.05$

\begin{tabular}{lllll}
\hline Parameters & $G M$ & $G M+\mathrm{NaCl}$ & $\mathrm{GS}$ & $\mathrm{GS}+\mathrm{NaCl}$ \\
\hline $\mathrm{Pl}_{\text {total }}$ & $1.82 \pm 0.33 \mathrm{a}$ & $0.58 \pm 0.21 \mathrm{~b}$ & $2.11 \pm 0.19 \mathrm{a}$ & $2.03 \pm 0.13 \mathrm{a}$ \\
Plabs & $2.64 \pm 0.48 \mathrm{a}$ & $0.78 \pm 0.12 \mathrm{~b}$ & $2.87 \pm 0.58 \mathrm{a}$ & $2.69 \pm 0.41 \mathrm{a}$ \\
ETo/TRo & $0.54 \pm 0.02 \mathrm{a}$ & $0.43 \pm 0.03 \mathrm{~b}$ & $0.56 \pm 0.02 \mathrm{a}$ & $0.54 \pm 0.04 \mathrm{a}$ \\
REo/ETo & $0.41 \pm 0.03 \mathrm{a}$ & $0.32 \pm 0.01 \mathrm{~b}$ & $0.42 \pm 0.03 \mathrm{a}$ & $0.41 \pm 0.01 \mathrm{a}$ \\
\hline
\end{tabular}

\section{$\mathrm{Fv} / \mathrm{Fm}$ with presence of chloramphenicol}

Chloramphenicol, an inhibitor of D1 protein de novo synthesis, was used to clarify whether the difference of D1 protein de novo synthesis was responsible for unequal PSII photoinhibition in Glycine max and Glycine soja. Due to the application of chloramphenicol, Fv/Fm was greater decreased to a similar level in Glycine max and Glycine soja upon salt stress (Fig. 5), suggesting that the negative effects of salt stress was imposed on PSII mainly by impeding D1 protein repair.

\section{Lipid peroxidation and $\mathrm{H}_{2} \mathrm{O}_{2}$ content}

Malondialdehyde (MDA) content reflects the level of lipid peroxidation in plant tissue. After 9 days of salt stress, MDA and $\mathrm{H}_{2} \mathrm{O}_{2}$ content was significantly increased in the leaves of Glycine max in contrast to no remarkable change in the leaves of Glycine soja, and consistently, histochemical staining with 3,3-diaminobenzidine also suggested the obvious increase of $\mathrm{H}_{2} \mathrm{O}_{2}$ content in the leaves of Glycine max rather than Glycine soja (Fig. 6).

\section{Ultrastructure of leaf chloroplast}

After 9 days of salt stress, no obvious change occurred in mesophyll cell and chloroplast ultrastructure in Glycine soja, illustrating its high salt tolerance (Fig. 7). Nonetheless, chloroplast tended to separate from cell wall with great reduction of starch granules in Glycine max upon salt stress, and in addition to disintegrated chloroplast envelope, distended and loosen thylakoids were also detected (Fig. 7). The damage on chloroplast ultrastructure was accordant with salt-induced great depression on photosystems performance in Glycine max.

\section{Discussion}

As with our previous study [14], tremendous decrease in Pn with stomatal closure was verified in Glycine max and Glycine soja under severe salt stress (Fig. 1a, b). The great depression on $\mathrm{CO}_{2}$ assimilation posed a big threat to photosynthetic apparatus by increasing the possibility of ROS generation through feedback inhibition on photosynthetic electron transport. Actually, elevated lipid peroxidation and $\mathrm{H}_{2} \mathrm{O}_{2}$ concentration confirmed salt-induced oxidative stress in the leaves of Glycine $\max$ (Fig. 6). Photosystems photoinhibition usually arises in parallel with elevated leaf lipid peroxidation under environmental stresses, and notably, the negative correlation of ROS production with PSI and PSII photochemical capacity under salt stress has been evidenced $[18,25,28,44]$. As a result, unchanged lipid peroxidation and $\mathrm{H}_{2} \mathrm{O}_{2}$ concentration implied that photosystems were less endangered by salt-induced oxidative stress in Glycine soja than Glycine max. 


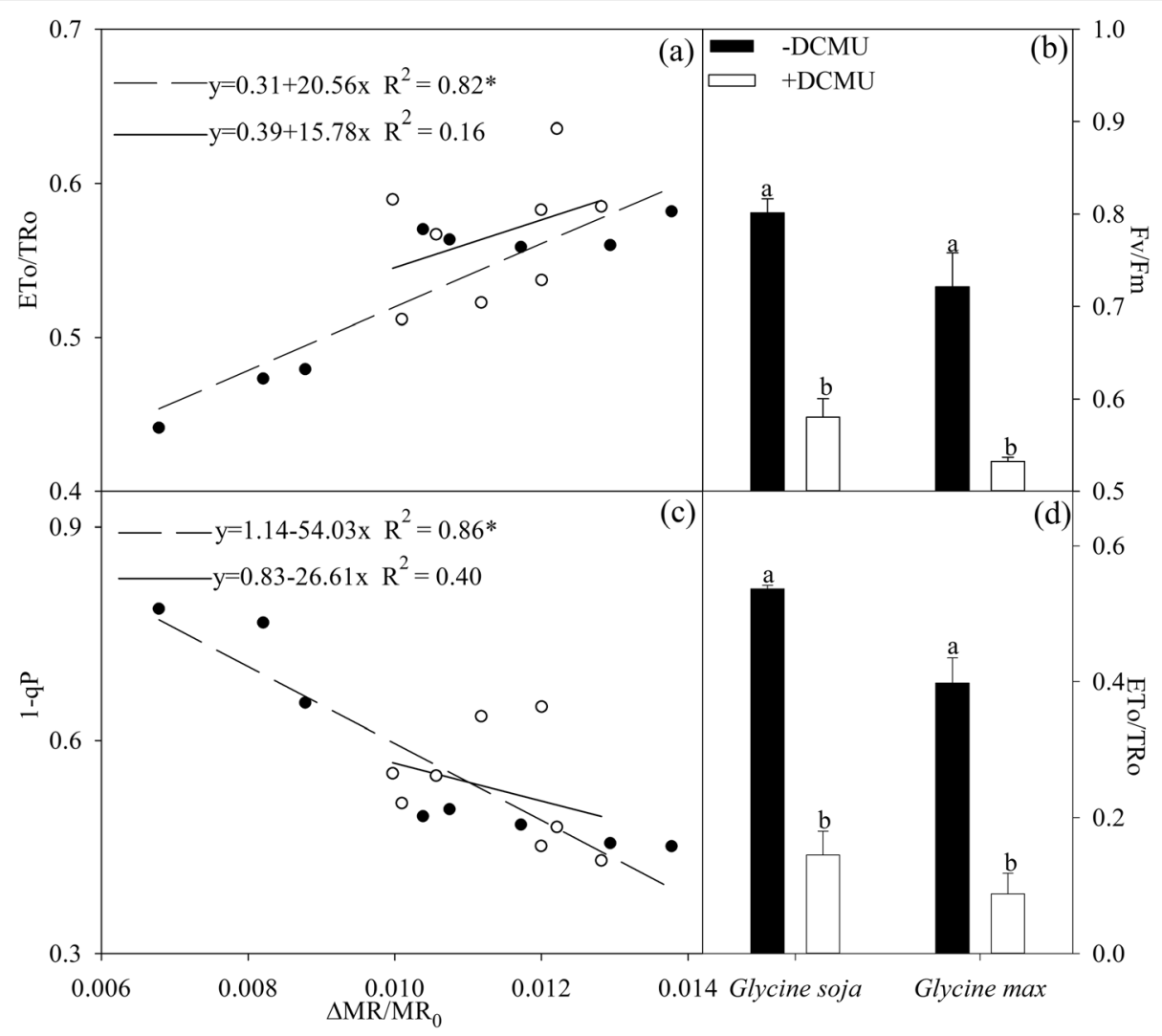

Fig. 4 Regression analysis of the maximal photochemical efficiency of PSII ( $\left.\triangle M R / M R_{0}\right)$ with probability that an electron moves beyond primary quinone (ETo/TRo, a) and PSIl excitation pressure (1-qP, c) in Glycine max (closed symbols) and Glycine soja (open symbols). * Indicates that the correlation was significant at $P<0.01$. The maximal photochemical efficiency of PSII (Fv/Fm, b) and ETo/TRo (d) in Glycine max and Glycine soja in the absence or presence of 3-(3,4-dichlorfenyl)-1,1-dimethylkarbonyldi-amid (DCMU) after 9 days of salt stress with $300 \mathrm{mM} \mathrm{NaCl}$. For reagent treatment, the leaves after 6 days of salt stress with $300 \mathrm{mM} \mathrm{NaCl}$ were immersed in 0 or $70 \mu \mathrm{M} \mathrm{DCMU}$ for $3 \mathrm{~h}$ in the dark. The data of Fv/Fm (b) and ETo/TRo $(\mathbf{d})$ indicate the mean of five replicates $( \pm \mathrm{SD})$, and different letters on error bars indicate significant difference between DCMU treatment and control at $P<0.05$

Consistently, salt-induced PSII and PSI photoinhibition was noted in Glycine max rather than Glycine soja according to the variation of $\mathrm{Fv} / \mathrm{Fm}$ and $\triangle \mathrm{MR} / \mathrm{MR}_{0}$, and less decrease in $\mathrm{PI}_{\text {total }}$ corroborated better performance of photosynthetic apparatus in Glycine soja (Fig. 3c, e, f). In particular, salt-induced destruction of chloroplast and thylakoid ultrastructure confirmed the serious depression on photosystems performance in Glycine max (Fig. 7). PSI vulnerability usually lies in sensitive plants and seems as a feasible criterion for discerning plant tolerance to abiotic stresses because of its threat to the entire photosynthetic apparatus [28]. In this study, PSI stability was defined in Glycine soja under salt stress due to unobvious change in $\triangle \mathrm{MR} / \mathrm{MR}_{0}$ and PsaA abundance (Fig. 3a, f). In contrast, PSI vulnerability was observed in Glycine max, indicated by salt-induced decrease in $\triangle \mathrm{MR} / \mathrm{MR}_{0}$ at day 3 before the occurrence of PSII photoinhibition (Fig. 3e, f). Therefore, high salt adaptability should include PSI stability in the halophytic soybean. $\mathrm{PI}_{\mathrm{abs}}$ comprehensively reflects PSII performance and is more sensitive than $\mathrm{Fv} / \mathrm{Fm}[45,46]$. After 3 days of salt stress, PSII performance was already depressed not only in Glycine max but also in Glycine soja, and less decease in $\mathrm{PI}_{\text {abs }}$ suggested greater PSII stability in Glycine soja (Fig. 3d). Under salt stress, PSII donor and acceptor sides were initially impaired with declined amount of active PSII reaction centers in Glycine $\max$ (Fig. 3g, i, j), and PSII reaction center was damaged later due to lowered Fv/Fm and PsbA abundance (Fig. 3b, e). Comparatively, only PSII acceptor side was influenced by salt stress in Glycine soja, and the influence was lighter than that in Glycine max in light of less decrease in ETo/TRo and smaller elevation of J step (Fig. 2a, b and 3i). Similar to previous study, PSII stability was verified in the halophytic soybean under salt stress [14, 24], however, the rapid response from PSII acceptor side was revealed in this study. Delayed chlorophyll $a$ fluorescence in microsecond domain is mostly related to $\mathrm{Z}^{+} \mathrm{Q}_{\mathrm{A}}{ }^{-}$state of PS II [47]. The occurrence of $I_{1}$ peak in DF transients mainly results from accumulation of $\mathrm{S}_{3} \mathrm{Z}^{+} \mathrm{P} 680 \mathrm{Q}_{\mathrm{A}}{ }^{-}$state, which 


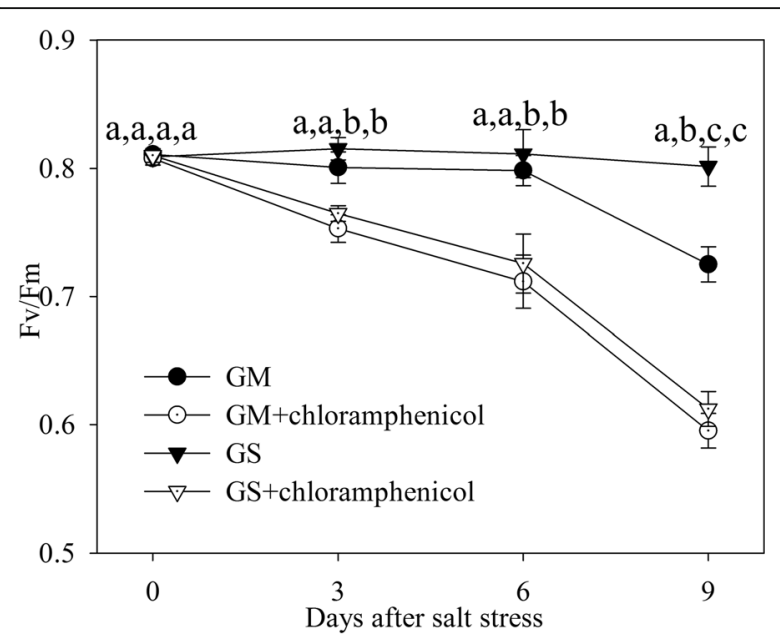

Fig. 5 The maximal photochemical efficiency of PSII (FV/Fm) in Glycine max (circles) and Glycine soja (triangles) exposed to $300 \mathrm{mM}$ $\mathrm{NaCl}$ in the absence (closed symbols) or presence (open symbols) of chloramphenicol. For reagent treatment, leaves of Glycine max and Glycine soja were immersed in 0 or $1 \mathrm{mM}$ chloramphenicol for $3 \mathrm{~h}$ in the dark before salt stress. Data in the figure indicate the mean of five replicates $( \pm S D)$. Different letters indicate significant difference among GS, GM, GS + chloramphenicol and GM + chloramphenicol at $P<0.05$ relates to active reaction centers and electron transfer capacity at both donor and acceptor sides of PSII [47, 48]. Under salt stress, large decrease in $I_{1}$ corroborated the damage on PSII components including reaction center, donor and acceptor sides in Glycine max, whereas slight decrease in $\mathrm{I}_{1}$ was coincident with the mild inhibition on electron transport at PSII acceptor side in Glycine soja (Fig. 2e, f). Overall, PSI stability and rapid response of PSII acceptor side were illustrated in the halophytic soybean under salt stress.

As reported in previous studies, antioxidant enzymes were stimulated by salt stress to a higher level in Glycine soja than Glycine max [14]. Apart from the stronger antioxidant protection, photosystems coordination also played an important role in counteracting photosystems photoinhibtion in Glycine soja exposed to severe salt stress. PSI photoinhibition derives from oxidation of iron-sulfur protein by ROS generated through Mehler reaction at PSI acceptor side, and the electron flow from PSII is essential for PSI photoinhibition [22]. Upon saltinduced great decrease in $\mathrm{CO}_{2}$ assimilation, the rapid response of PSII acceptor side restricted electron flow to PSI in Glycine soja and could help protect against PSI
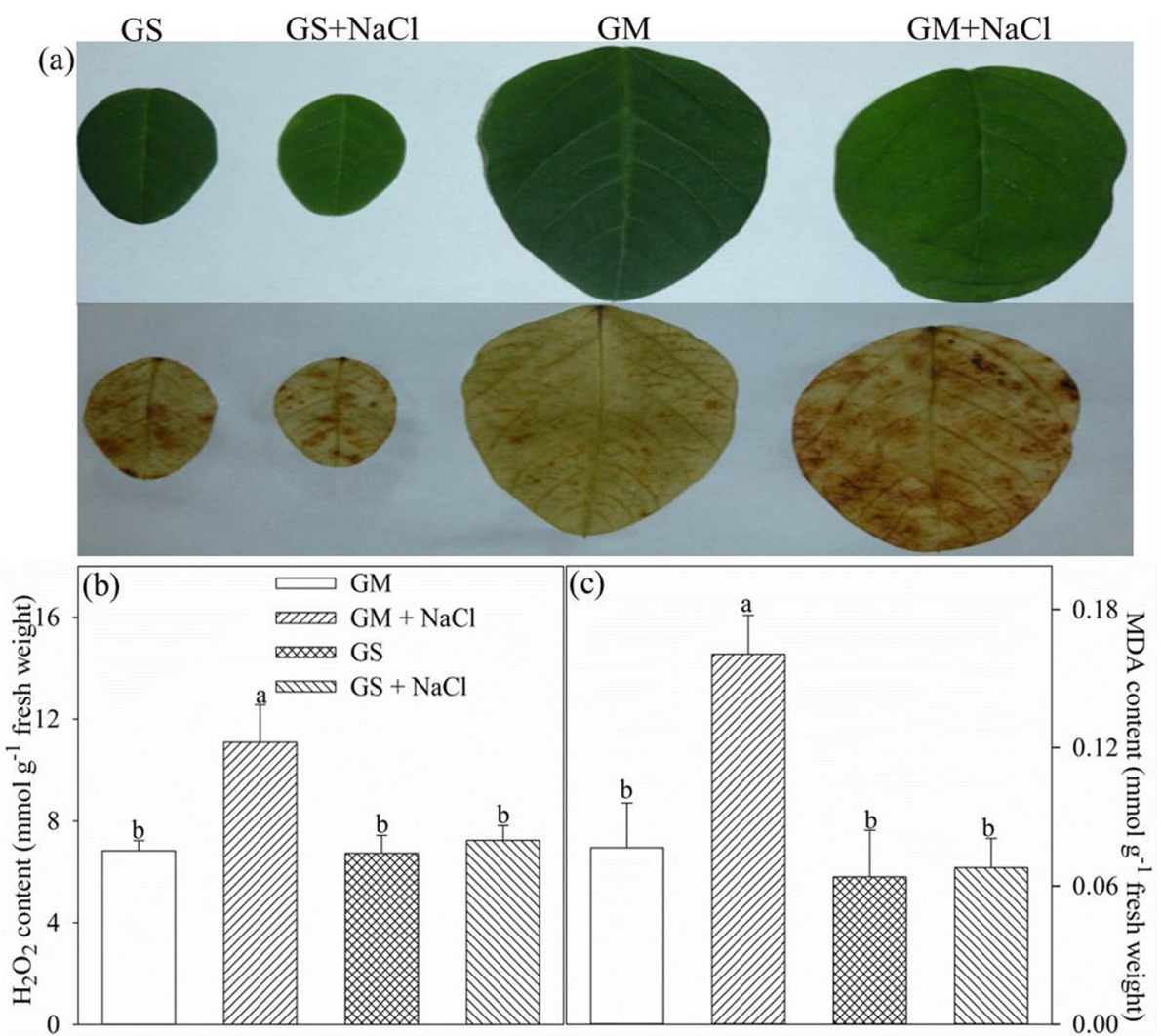

Fig. 6 Histochemical detection of $\mathrm{H}_{2} \mathrm{O}_{2}(\mathbf{a})$, malondialdehyde (MDA, b) and $\mathrm{H}_{2} \mathrm{O}_{2}$ (c) contents in the leaves of Glycine max (GM) and Glycine soja (GS) after 9 days of salt stress with $300 \mathrm{mM} \mathrm{NaCl}$. Data in the figure indicate the mean of five replicates $( \pm \mathrm{SD})$, and different letters on error bars indicate significant difference between salt treatment and control at $P<0.05$ 


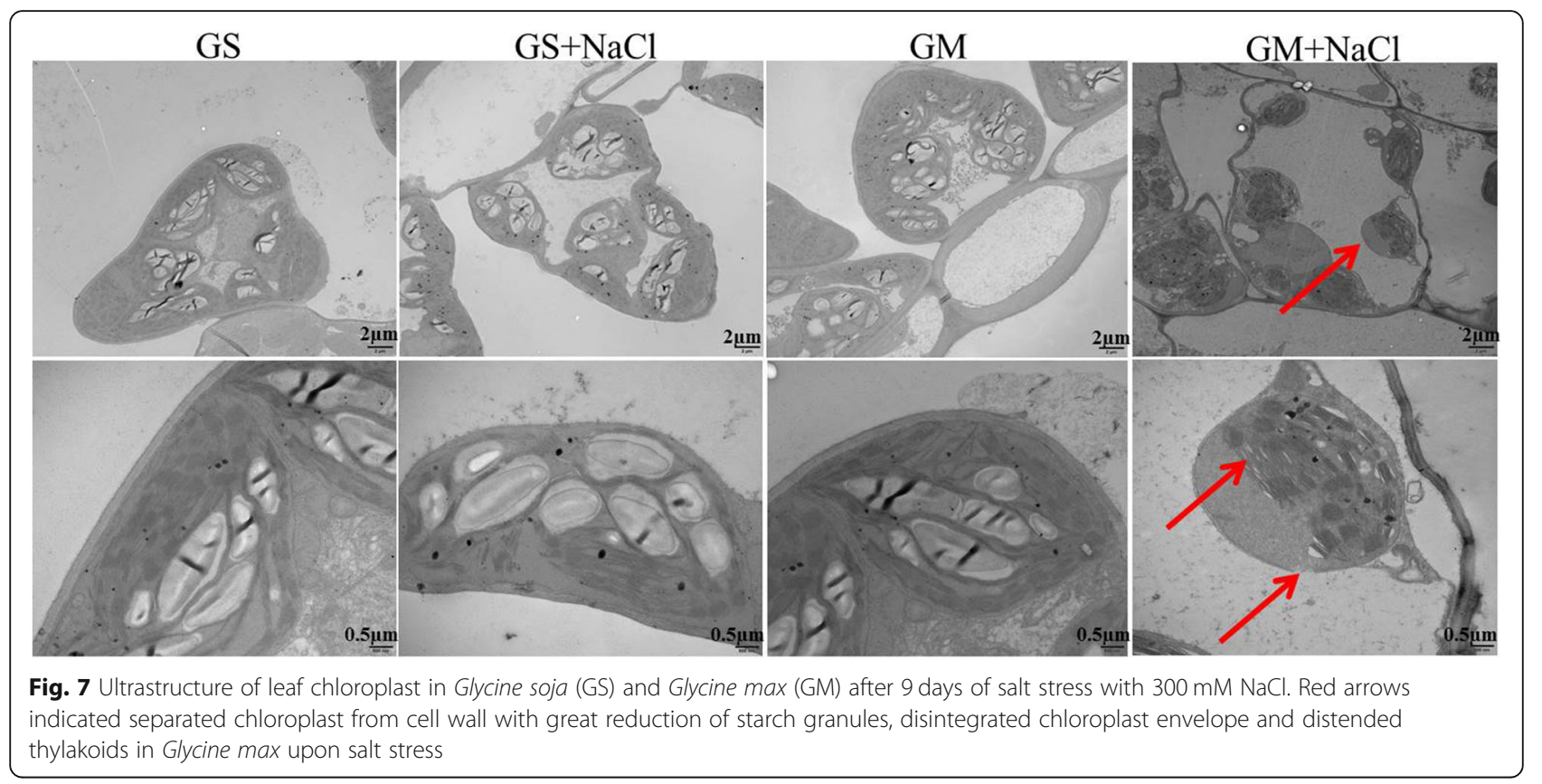

inhibition by reducing ROS generation (Fig. 1d). The experiment with DCMU application, which simulated the suppression of electron transport at PSII acceptor side caused by PSI photoinhibition, demonstrated that PSI photoinhibition accelerated PSII photoinhibition (Fig. 4b, d). PSI activity bore no relation to PSII excitation pressure and electron transport at PSII acceptor side in Glycine soja according to the correlation analysis of $\triangle \mathrm{MR} / \mathrm{MR}_{0}$ with 1 -qP and ETo/TRo (Fig. 4a, c). Therefore, PSI stability was conductive to preventing the occurrence of PSII photoinhibition by alleviating feedback inhibition on electron transport in Glycine soja under salt stress. Inversely, PSI vulnerability elevated PSII excitation pressure in Glycine max under salt stress by inducing over-reduction of PSII acceptor side, indicated by positive correlation between $\triangle \mathrm{MR} / \mathrm{MR}_{0}$ and ETo/TRo and negative correlation between $\triangle \mathrm{MR} / \mathrm{MR}_{0}$ and 1 -qP (Figs. 1c and 4a, c), and eventually resulted in PSII photoinhibition (Fig. 3e). The difference of salt-induced PSII photoinhibition between Glycine max and Glycine soja originated from the repair of photodamaged PSII rather than direct photodamage to PSII, because Fv/Fm decreased to the same level in presence of chloramphenicol (Fig. 5). The declined PSI re-reduction amplitude in MR transients conformed to PSII inactivation in Glycine $\max$ (Fig. 2c, d), as PSI re-reduction process mainly depended on electron donation from PSII. In spite of great restriction on electron flow to PSI due to PSII inactivation, PSI oxidation amplitude in MR transient was still depressed (Fig. 2c, d), which verified greater damage on PSI than PSII. $\mathrm{I}_{2}$ phase in DF transients is related to the prolonged reopening of PSII reaction centers by electron transfer from reduced quinone to plastoquinone (PQ) before full reduction of PQ pool [43, 44, 49]. In agreement with elevated I step and decreased REo/ ETo, the decrease in $I_{2}$ also suggested that PQ reoxidation was inhibited due to greater damage on PSI (Fig. 2e, f). Therefore, the passive PSII photoinhibition could not effectively defend oxidative injury of PSI in Glycine max under salt stress. Nonetheless, salt stress also elevated I step and induced decrease in REo/ETo and $\mathrm{I}_{2}$ in Glycine soja (Figs. 2a, b, e, f and 3j), and the declined PQ re-oxidation seemed contradictory to unchanged PSI activity. PQ is located in cytochrome b6f complex (cyt b6f) by which electron transport from PSII to PSI is bridged, and the soluble primary PSI acceptor, Ferredoxin, binds the stromal site of cyt b6f to trigger PSI cyclic electron flow [50]. PSI cyclic electron flow is an important photoprotective pathway in plants under abiotic stress due to the reduction of electron donation to PSI and production of ATP for repairing photodamaged PSII [51-54]. We supposed that the declined PQ re-oxidation resulted from enhanced binding of cyt b6f with Fd for promoting PSI cyclic electron flow in Glycine soja under salt stress and caused feedback inhibition on electron transport beyond $\mathrm{Q}_{\mathrm{A}}$ at PSII acceptor side. This inference should be established in future study by exploring the relation between photosystem coordination and PSI cyclic electron flow. However, at least, rapid recovery of ETo/TRo and REo/ETo after salt stress supported that it was a positive response to limit electron transport between PSII and PSI in Glycine soja for protecting photosynthetic apparatus (Table 1). 


\section{Conclusion}

To summarize, photosystems coordination which was dependent on PSI stability and rapid response of PSII acceptor side contributed to defending salt-induced oxidative stress on photosynthetic apparatus in Glycine soja. This study can deepen the knowledge about salt tolerance mechanism in the halophyte.

\section{Methods}

\section{Plant material and treatment}

Glycine soja is a halophytic soybean native to coastal saline soil in Yellow River Delta, China, and the seeds of Glycine soja were carefully collected from wild plants near the Yellow River Delta coastal wetland ecological experimental station, Chinese Academy of Sciences $\left(\mathrm{N} 37^{\circ} 45^{\prime}, \mathrm{E} 118^{\circ} 58^{\prime}\right)$. The collected seeds have been identified by Prof. Hualing $\mathrm{Xu}$ and deposited in Dongying academy of agricultural sciences. Experimental research on plants including collection of plant material in this study did not violate any guideline or local legislation. Special permissions and ethical approval were not required to collect and use this wild soybean. Glycine $\max$ is a major cultivated soybean in China, and the seeds of Glycine max were obtained by sexual hybridization with yudou8 and zhongzuo90052-76 as the parents. The seeds of Glycine max were provided by Shandong academy of agricultural sciences. The seeds of Glycine soja and Glycine max are shown in Additional file 1: Figure S1, and the seed specimens were, respectively, conserved in Dongying academy of agricultural sciences and Shandong academy of agricultural sciences without voucher number.

The protocols for seed germination and seedling culture have been reported in our previous study [14]. In July 7, 2017, the seeds of Glycine max were soaked in distilled water for $8 \mathrm{~h}$, while the seeds of Glycine soja were soaked in concentrated sulfuric acid for $10 \mathrm{~min}$ to remove the hard shell over the seeds. The seeds were transferred to petri dishes and laid between two sheets of filter paper for germinating at $25^{\circ} \mathrm{C}$ in the dark, and Hoagland nutrient solution ( $\mathrm{pH}$ 5.7) was sprayed to keep the filter paper wet. The Hoagland nutrient solution contains calcium nitrate tetrahydrate $\left(945 \mathrm{mg} \mathrm{L}^{-1}\right)$, disodium EDTA $\left(37 \mathrm{mg} \mathrm{L}^{-1}\right)$, potassium nitrate $\left(506 \mathrm{mg} \mathrm{L}^{-1}\right)$, ferrous sulfate heptahydrate $\left(28 \mathrm{mg} \mathrm{L}^{-1}\right)$, ammonium nitrate $(80$ $\left.\mathrm{mg} \mathrm{L}^{-1}\right)$, boric acid $\left(6.2 \mathrm{mg} \mathrm{L}^{-1}\right)$, potassium iodide $(0.83$ $\left.\mathrm{mg} \mathrm{L}^{-1}\right)$, manganese sulfate $\left(22 \mathrm{mg} \mathrm{L}^{-1}\right)$, potassium dihydrogen phosphate $\left(136 \mathrm{mg} \mathrm{L}^{-1}\right)$, zinc sulfate $\left(8.6 \mathrm{mg} \mathrm{L}^{-1}\right)$, magnesium sulphate $\left(493 \mathrm{mg} \mathrm{L}^{-1}\right)$, sodium molybdate (0.25 $\left.\mathrm{mg} \mathrm{L}^{-1}\right)$, copper sulphate $\left(0.025 \mathrm{mg} \mathrm{L}^{-1}\right)$ and cobalt chloride $\left(0.025 \mathrm{mg} \mathrm{L}^{-1}\right)$. After germination, the seedlings were cultured with the same method reported in our previous study [14]. One month later, salt treatment was conducted on uniform plants by adding $\mathrm{NaCl}$ to Hoagland nutrient solution ( $\mathrm{pH}, 5.7) . \mathrm{NaCl}$ concentration in Hoagland nutrient solution $(\mathrm{pH}, 5.7)$ was gradually elevated by $50 \mathrm{mM}$ every day to reach the final treatment concentration $(300 \mathrm{mM} \mathrm{NaCl})$. The newest fully expanded leaves were sampled for measuring physiological and biochemical parameters. After 9 days of salt stress, $\mathrm{NaCl}$ in the culture medium were leached completely with Hoagland nutrient solution for examining the recovery of photosystem performance, as there was a small hole in the bottom of each pot for leaching salt.

\section{Measurements of gas exchange and modulated chlorophyll fluorescence}

Gas exchange and modulated chlorophyll fluorescence parameters were simultaneously detected by using an open photosynthetic system (LI-6400XTR, Li-Cor, Lincoln, NE, USA) equipped with a fluorescence leaf chamber (6400-40 LCF, Li-Cor). The temperature and $\mathrm{CO}_{2}$ concentration were respectively set at $25^{\circ} \mathrm{C}$ and $400 \mu \mathrm{mol} \mathrm{mol}^{-1}$ in the leaf cuvette. Pn and $\mathrm{g}_{\mathrm{s}}$ were simultaneously recorded. Modulated chlorophyll fluorescence was also recorded for calculating ETR and 1-qP according to previous studies $[25,55]$.

\section{Measurements of prompt chlorophyll fluorescence, modulated $820 \mathrm{~nm}$ reflection and delayed chlorophyll fluorescence transients}

By using a multifunctional plant efficiency analyzer (MPEA, Hansatech, UK), PF, DF and MR transients were simultaneously recorded in the first $1 \mathrm{~s}$ illumination with red light, and MR signals were still detected in the following $10 \mathrm{~s}$ far red illumination. The redox state of PSI reaction center under continuous light can be detected by monitoring $820 \mathrm{~nm}$ reflection [40]. $\Delta \mathrm{MR} / \mathrm{MR}_{0}, \mathrm{Fv} / \mathrm{Fm}, \mathrm{V}_{\mathrm{k}}$, RC/ABS, ETo/TRo, REo/ETo, $\mathrm{PI}_{\text {abs }}$ and $\mathrm{PI}_{\text {total }}$ were calculated according to previous studies $[40,56,57]$.

All redox reactions of the photosynthetic electron transport are reversible, and the back electron transfer and charge recombination in PSII reaction center lead to delayed fluorescence emission from repopulated excited chlorophyll [47]. DF signals are recorded in dark intervals for excluding PF interference under the light [47, 57]. In this study, DF signals in microsecond domain were collected at $20 \mu \mathrm{s}$ after turning off actinic light for constructing DF transients.

\section{Measurements of MDA and $\mathrm{H}_{2} \mathrm{O}_{2}$ contents and histochemical detection of $\mathrm{H}_{2} \mathrm{O}_{2}$}

MDA content was measured by thiobarbituric acid reaction method for indicating lipid peroxidation degree [58]. Leaf tissues $(0.5 \mathrm{~g})$ were ground under liquid nitrogen and homogenized in $5 \mathrm{~mL} 0.1 \%$ TCA. The homogenate was centrifuged at $10000 \times g$ and $4{ }^{\circ} \mathrm{C}$ for $10 \mathrm{~min}$ to collect the supernatant for measuring MDA and 
$\mathrm{H}_{2} \mathrm{O}_{2}$ contents [25]. Leaves were vacuum-infiltrated with $0.1 \mathrm{mg} \mathrm{ml}^{-1}$ 3, 3-diaminobenzidine in $50 \mathrm{mM}$ trisacetate solution $(\mathrm{pH}, 3.8)$ and incubated at room temperature in the dark for $24 \mathrm{~h}$. Thereafter, the leaves were decolorized by immersion in boiling ethanol $(80 \%)$ for $10 \mathrm{~min}$ and photographed [59].

\section{Isolation of thylakoid membranes and western blot}

As with the method of Yan et al. [28], western blots of PsbA and PsaA were carried out through the procedures including protein extraction, SDS-PAGE gel, protein transfer to polyvinylidene fluoride membranes, incubation with specific antibodies and signal detection by chemiluminescence.

\section{Observation of chloroplast ultrastructure}

Similar to Oustric et al. [60] with small modification, leaf pieces $\left(1 \mathrm{~mm}^{2}\right)$ were sampled, fixed in $2.5 \%$ glutaraldehyde in $100 \mathrm{mM}$ phosphate buffer $(\mathrm{pH}, 7.2)$ for $2 \mathrm{~h}$ at room temperature and washed with the same buffer. The samples were post-fixed in $1 \%$ osmic acid in 100 $\mathrm{mM}$ phosphate buffer $(\mathrm{pH}, 7.2)$ at room temperature for $4 \mathrm{~h}$, parched through a graded ethanol series (50-100\%) and embedded in Spurr's epoxy resin. An ultramicrotome (Leica ultracut R, Germany) was used to obtain ultra-sections $(70 \mathrm{~nm})$, and then, chloroplast ultrastructure was detected by a transmission electron microscope (JEM-1230, Japan) after staining these ultra-sections with uranyl acetate and lead phosphate.

\section{Statistical analysis}

One-way ANOVA was carried out by using SPSS 16.0 (SPSS Inc., Chicago, IL, USA) for all sets of data. The values presented are the means of measurements with five replicate plants, and comparisons of means were determined through LSD test. Difference was considered significant at $P<0.05$.

\section{Supplementary information}

Supplementary information accompanies this paper at https://doi.org/10. 1186/s12870-020-02371-x.

Additional file 1 : Figure S1. Glycine soja and Glycine max seeds, transients of prompt chlorophyll $a$ fluorescence in Glycine soja and Glycine max before salt treatment, and the growth of Glycine soja and Glycine max in an artificial climatic chamber.

Additional file $\mathbf{2}$ : Figure S2. The original image of western blot of reaction center proteins of PSII (PsbA) protien in Glycine max (GM) and Glycine soja (GS) under salt stress. A red arrow indicates the cropped signals which were used in Fig. 3b.

Additional file $\mathbf{3}$ : Figure $\mathbf{S 3}$. The original image of western blot of reaction center proteins of PSI (PsaA) protien in Glycine max (GM) and Glycine soja (GS) under salt stress. A red arrow indicates the cropped signals which were used in Fig. 3a.

\section{Abbreviations}

Cyt b6f: Cytochrome b6f complex; ETo/TRo: Probability with which an electron moves beyond primary quinone; ETR: PSII electron transport rate;
Fv/Fm: The maximal quantum yield of PSIl; $g_{s}$ : Stomatal conductance; MDA: Malondialdehyde; Pn: Photosynthetic rate; Plabs: PSII performance index; PI total: Total performance index; PSI: Photosystem I; PSII: Photosystem II; RC/ABS: Primary quinone reducing reaction centers per PSII antenna chlorophyll; PQ: Plastoquinone; REo/ETo: Probability with which an electron from the intersystem electron carriers is transferred to reduce end electron acceptors at the PSI acceptor side; $\mathrm{Q}_{\mathrm{A}}$ : Primary quinone; ROS: Reactive oxygen species; $V_{k}$ : Variable fluorescence intensity at $K$ step; $\triangle M R / M R_{0}$ : The maximal photochemical capacity of PSI; ФPSII: Actual photochemical efficiency of PSII; 1-qP: Excitation pressure of PSII

\section{Acknowledgements}

We thank Prof. Hualing Xu for identifying the Glycine soja seeds.

\section{Authors' contributions}

$\mathrm{KY}$ designed the experiment, performed the experiment and data analysis, wrote and revised the manuscript. WH and LB participated in the experiment. ZZ participated in the experiment and helped revise the manuscript. XT and MA participated in data analysis. LL helped polish the language. GH proposed some critical suggestions and reviewed the manuscript. All authors have read the manuscript and approved the final version of the manuscript.

\section{Funding}

This research was jointly financed by the National Key Research \& Development Program in China (2019YFD1002702), National Natural Science Foundation of China (41201292), Shandong Provincial Natural Science Foundation, China (ZR2017QC005), Yantai Science and Technology Innovation Development Plan (2020MSGY065), Key Deployment Project of Chinese Academy of Sciences (KFZD-SW-113), Opening Foundation of the State Key Laboratory of Crop Biology, Shandong Agricultural University (2016KF07) and Shandong Key Research and Development Plan (2017CXGC0316). The funders were not involved in the experiment design, data collection and analysis, preparation of the manuscript, and decision to publish.

\section{Availability of data and materials}

The datasets used and/or analysed during the current study are available from the corresponding author on reasonable request.

Ethics approval and consent to participate

Not applicable.

\section{Consent for publication}

Not applicable.

\section{Competing interests}

The authors declare that they have no competing interests.

\section{Author details}

${ }^{1}$ CAS Key Laboratory of Coastal Environmental Processes and Ecological Remediation, Yantai Institute of Coastal Zone Research (YIC), Chinese Academy of Sciences(CAS), Shandong Key Laboratory of Coastal Environmental Processes, YICCAS, Yantai, Shandong 264003, P. R. China. ${ }^{2}$ College of Life Sciences, Yantai University, Yantai 264005, P. R. China. ${ }^{3}$ State Key Laboratory of Crop Biology, Shandong Key Laboratory of Crop Biology, College of Life Sciences, Shandong Agricultural University, Tai'an 271018, P. R. China. ${ }^{4}$ School of Agriculture, Ludong University, Yantai 264025, P. R. China.

Received: 7 August 2019 Accepted: 30 March 2020

Published online: 10 April 2020

\section{References}

1. Nikalje GC, Srivastava AK, Pandey GK, Suprasanna P. Halophytes in biosaline agriculture: mechanism, utilization, and value addition. Land Degrad Dev. 2017;29:1081-95.

2. Fedoroff NV, Battisti DS, Beachy RN, Cooper PJM, Fischhoff DA, Hodges CN, Knauf VC, Lobell D, Mazur BJ, Molden D, Reynolds MP, Ronald PC, Rosegrant MW, Sanchez PA, Vonshak A, Zhu JK. Radically rethinking agriculture for the 21st century. Science. 2010;327:833-4. 
3. Panta S, Flowers T, Lane P, Doyle R, Haros G, Shabala S. Halophyte agriculture: success stories. Environ Exp Bot. 2014;107:71-83.

4. Rozema J, Flowers T. Ecology crops for a salinized world. Science. 2008;322: 1478-80.

5. Ventura Y, Eshel A, Pasternak D, Sagi M. The development of halophytebased agriculture: past and present. Ann Bot. 2015;115:529-40.

6. Gill SS, Tuteja N. Reactive oxygen species and antioxidant machinery in abiotic stress tolerance in crop plants. Plant Physiol Biochem. 2010;48:909-30.

7. Hossain MS, Dietz KJ. Tuning of redox regulatory mechanisms, reactive oxygen species and redox homeostasis under salinity stress. Front Plant Sci. 2016;7:548.

8. Bose J, Moreno AR, Shabala S. ROS homeostasis in halophytes in the context of salinity stress tolerance. J Exp Bot. 2014;65:1241-57.

9. Chen M, Yang Z, Liu J, Zhu T, Wei X, Fan H, Wang B. Adaptation mechanism of salt excluders under saline conditions and its applications. Int J Mol Sci. 2018;19:3668

10. Shabala S, Bose J, Hedrich R. Salt bladders: do they matter? Trends Plant Sci. 2014;19:687-91.

11. Song J, Wang B. Using euhalophytes to understand salt tolerance and to develop saline agriculture: Suaeda salsa as a promising model. Ann Bot 2015;115:541-53.

12. Wu H. Plant salt tolerance and $\mathrm{Na}^{+}$sensing and transport. Crop J. 2018;6: 215-25.

13. Aparicio C, Urrestarazu M, Cordovilla MD. Comparative physiological analysis of salinity effects in six olive genotypes. Hortscience. 2014;49:901-4.

14. Chen P, Yan K, Shao H, Zhao S. Physiological mechanisms for high salt tolerance in wild soybean (Glycine soja) from yellow river delta, China: photosynthesis, osmotic regulation, ion flux and antioxidant capacity. PLoS One. 2013;8:e83227.

15. Kalaji HM, Govindjee, Bosa K, Koscielniak J, Golaszewska KZ. Effects of salt stress on photosystem II efficiency and CO2 assimilation of two Syrian barley landraces. Environ Exp Bot. 2011;73:64-72.

16. Stepien P, Johnson GN. Contrasting responses of photosynthesis to salt stress in the glycophyte arabidopsis and the halophyte Thellungiella: role of the plastid terminal oxidase as an alternative electron sink. Plant Physiol. 2009;149:1154-65

17. Yan K, Shao HB, Shao CY, Chen P, Zhao SJ, Brestic M, Chen XB. Physiological adaptive mechanisms of plants grown in saline soil and implications for sustainable saline agriculture in coastal zone. Acta Physiol Plant. 2013;35:2867-78.

18. Yan K, Wu C, Zhang L, Chen X. Contrasting photosynthesis and photoinhibition in tetraploid and its autodiploid honeysuckle (Lonicera japonica thunb.) under salt stress. Front Plant Sci. 2015;6:227.

19. Loreto F, Centritto M, Chartzoulakis K. Photosynthetic limitations in olive cultivars with different sensitivity to salt stress. Plant Cell Environ. 2003;26: 595-601.

20. Yang XH, Liang Z, Wen XG, Lu CM. Genetic engineering of the biosynthesis of glycinebetaine leads to increased tolerance of photosynthesis to salt stress in transgenic tobacco plants. Plant Mol Biol. 2008;66:73-86.

21. Takahashi S, Murata N. How do environmental stresses accelerate photoinhibition? Trends Plant Sci. 2008:13:178-82.

22. Sonoike K. Photoinhibition of photosystem I. Physiol Plant. 2011;142:56-64

23. Yang $Y$, Yan CQ, Cao BH, Xu HX, Chen JP, Jiang DA. Some photosynthetic responses to salinity resistance are transferred into the somatic hybrid descendants from the wild soybean Glycine cyrtoloba ACC547. Physiol Plant. 2007;129:658-69.

24. Xue Z, Zhao S, Gao H, Sun S. The salt resistance of wild soybean (Glycine soja Sieb. et Zucc. ZYD 03262) under $\mathrm{NaCl}$ stress is mainly determined by $\mathrm{Na}^{+}$distribution in the plant. Acta Physiol Plant. 2013;36:61-70.

25. Yan K, Bian T, He W, Han G, Lv M, Guo M, Lu M. Root abscisic acid contributes to defending photoinibition in Jerusalem artichoke (Helianthus tuberosus L.) under salt stress. Int J Mol Sci. 2018;19:3934.

26. Yan K, Zhao S, Liu Z, Chen X. Salt pretreatment alleviated salt-induced photoinhibition in sweet sorghum. Theor Exp Plant Physiol. 2015;27:119-29.

27. Zhang ZS, Yang C, Gao HY, Zhang LT, Fan XL, Liu MJ. The higher sensitivity of PSI to ROS results in lower chilling-light tolerance of photosystems in young leaves of cucumber. J Photochem Photobiol B-Biol. 2014;137:127-34.

28. Yan K, Zhao S, Cui M, Han G, Wen P. Vulnerability of photosynthesis and photosystem I in Jerusalem artichoke (Helianthus tuberosus L.) exposed to waterlogging. Plant Physiol Biochem. 2018:125:239-46.

29. Yan K, Chen P, Shao HB, Shao CY, Zhao SJ, Brestic M. Dissection of photosynthetic electron transport process in sweet sorghum under heat stress. PLoS One. 2013;8:e62100.
30. Yan K, Chen P, Shao HB, Zhao SJ. Characterization of photosynthetic electron transport chain in bioenergy crop Jerusalem artichoke (Helianthus tuberosus L.) under heat stress for sustainable cultivation. Ind Crop Prod. 2013:50:809-15.

31. Zivcak M, Brestic M, Kalaji HM, Govindjee. Photosynthetic responses of sunand shade-grown barley leaves to high light: Is the lower PSII connectivity in shade leaves associated with protection against excess of light? Photosynth Res. 2014;119:339-54.

32. Zhang ZS, Jia YJ, Gao HY, Zhang LT, Li HD, Meng QW. Characterization of PSI recovery after chilling-induced photoinhibition in cucumber (Cucumis sativus L.) leaves. Planta. 2011:234:883-9.

33. Zhang ZS, Jin LQ, Li YT, Tikkanen M, Li QM, Ai XZ, Gao HY. Ultraviolet-B radiation (UV-B) relieves chilling-light-induced PSI photoinhibition and accelerates the recovery of $\mathrm{CO}_{2}$ assimilation in cucumber (Cucumis sativus $\mathrm{L}$. leaves. Sci Rep. 2016;6:34455.

34. Lu KX, Ding WN, Zhu SH, Jiang DA. Salt-induced difference between Glycine cyrtoloba and G. max in anti-oxidative ability and $\mathrm{K}^{+} \mathrm{vs}$. $\mathrm{Na}^{+}$selective accumulation. Crop J. 2016:4:129-38.

35. Lu KX, Yang $Y$, He $Y$, Jiang DA. Induction of cyclic electron flow around photosystem I and state transition are correlated with salt tolerance in soybean. Photosynthetica. 2008:46:10-6.

36. Yang Y, Jiang DA, Xu HX, Yan CQ, Hao SR. Cyclic electron flow around photosystem I is required for adaptation to salt stress in wild soybean species Glycine cyrtoloba ACC547. Biol Plant. 2006;50:586-90.

37. Wei P, Che B, Shen L, Cui Y, Wu S, Cheng C, Liu F, Li MW, Yu B, Lam HM. Identification and functional characterization of the chloride channel gene, GSCLC-c2 from wild soybean. BMC Plant Biol. 2019;19:121.

38. Zhang XK, Zhou QH, Cao JH, Yu BJ. Differential cl-/salt tolerance and $\mathrm{NaCl}$ induced alternations of tissue and cellular ion fluxes in Glycine max, Glycine soja and their hybrid seedlings. J Agron Crop Sci. 2011;197:329-39.

39. Li PM, Cheng LL, Gao HY, Jiang CD, Peng T. Heterogeneous behavior of PSII in soybean (Glycine max) leaves with identical PSII photochemistry efficiency under different high temperature treatments. J Plant Physiol. 2009;166: 1607-15.

40. Schansker G, Srivastava A, Govindjee, Strasser RJ. Characterization of the 820-nm transmission signal paralleling the chlorophyll a fluorescence rise (OJIP) in pea leaves. Funct Plant Biol. 2003;30:785-96.

41. Schansker G, Toth SZ, Strasser RJ. Methylviologen and dibromothymoquinone treatments of pea leaves reveal the role of photosystem I in the Chl a fluorescence rise OJIP. Biochim Biophys Acta. 2005;1706:250-61.

42. Oukarroum A, Madidi SE, Strasser RJ. Differential heat sensitivity index in barley cultivars (Hordeum vulgare L.) monitored by chlorophyll a fluorescence OKJIP. Plant Physiol Biochem. 2016;105:102-8.

43. Oukarroum A, Goltsev V, Strasser RJ. Temperature effects on pea plants probed by simultaneous measurements of the kinetics of prompt fluorescence, delayed fluorescence and modulated $820 \mathrm{~nm}$ reflection. PLoS One. 2013;8:10.

44. Oukarroum A, Bussotti F, Goltsev V, Kalaji HM. Correlation between reactive oxygen species production and photochemistry of photosystems I and II in Lemna gibba L. plants under salt stress. Environ Exp Bot. 2015:109:80-8.

45. Zivcak M, Brestic M, Olsovska K, Slamka P. Performance index as a sensitive indicator of water stress in Triticum aestivum L. Plant Soil Environ. 2008:54: 133-9.

46. Zivcak M, Olsovska K, Slamka P, Galambosova J, Rataj V, Shao HS, Brestic M. Application of chlorophyll fluorescence performance indices to assess the wheat photosynthetic functions influenced by nitrogen deficiency. Plant Soil Environ. 2014;60:210-5.

47. Goltsev V, Zaharieva I, Chernev P, Strasser RJ. Delayed fluorescence in photosynthesis. Photosynth Res. 2009;101:217-32.

48. Gao J, Li P, Ma F, Goltsev V. Photosynthetic performance during leaf expansion in Malus micromalus probed by chlorophyll a fluorescence and modulated 820nm reflection. J Photochem Photobiol B-Biol. 2014;137:144-50.

49. Kalaji HM, Goltsev V, Bosa K, Allakhverdiev SI, Strasser RJ, Govindjee. Experimental in vivo measurements of light emission in plants: A perspective dedicated to david walker. Photosynth Res. 2012;114:69-96.

50. Joliot P, Joliot A. Cyclic electron flow in C3 plants. Biochim Biophys Acta. 2006:1757:362-8.

51. Wu X, Shu S, Wang Y, Yuan R, Guo S. Exogenous putrescine alleviates photoinhibition caused by salt stress through cooperation with cyclic electron flow in cucumber. Photosynth Res. 2019;141(3):303-14. 
52. Sun Y, Geng Q, Du Y, Yang X, Zhai H. Induction of cyclic electron flow around photosystem I during heat stress in grape leaves. Plant Sci. 2017;256: 65-71.

53. Huang W, Yang YJ, Zhang SB, Liu T. Cyclic electron flow around photosystem I promotes ATP synthesis possibly helping the rapid repair of photodamaged photosystem II at low light. Front Plant Sci. 2018:9:239.

54. Yang XQ, Zhang QS, Zhang D, Feng JX, Zhao W, Liu Z, Tan Y. Interaction of high seawater temperature and light intensity on photosynthetic electron transport of eelgrass (Zostera marina L.). Plant Physiol Biochem. 2018;132: 453-64.

55. Maxwell K, Johnson GN. Chlorophyll fluorescence - a practical guide. J Exp Bot. 2000;51:659-68

56. Yan K, Han G, Ren C, Zhao S, Wu X, Bian T. Fusarium solani infection depressed photosystem performance by inducing foliage wilting in apple seedlings. Front Plant Sci. 2018:9:479.

57. Strasser RJ, Michael MT, Qiang S, Goltsev V. Simultaneous in vivo recording of prompt and delayed fluorescence and $820 \mathrm{~nm}$ reflection changes during drying and after rehydration of the resurrection plant haberlea rhodopensis. Biochim Biophys Acta. 2010;1797:122.

58. Yan K, Zhao S, Bian L, Chen X. Saline stress enhanced accumulation of leaf phenolics in honeysuckle (Lonicera japonica thunb.) without induction of oxidative stress. Plant Physiol Biochem. 2017:112:326-34.

59. ThordalChristensen $\mathrm{H}$, Zhang ZG, Wei YD, Collinge DB. Subcellular localization of $\mathrm{H}_{2} \mathrm{O}_{2}$ in plants. $\mathrm{H}_{2} \mathrm{O}_{2}$ accumulation in papillae and hypersensitive response during the barley-powdery mildew interaction. Plant J. 1997:11:1187-94.

60. Oustric J, Quilichini Y, Morillon R, Herbette S, Luro F, Giannettini J, Berti L, Santini J. Tetraploid citrus seedlings subjected to long-term nutrient deficiency are less affected at the ultrastructural, physiological and biochemical levels than diploid ones. Plant Physiol Biochem. 2019;135:37284

\section{Publisher's Note}

Springer Nature remains neutral with regard to jurisdictional claims in published maps and institutional affiliations.

Ready to submit your research? Choose BMC and benefit from:

- fast, convenient online submission

- thorough peer review by experienced researchers in your field

- rapid publication on acceptance

- support for research data, including large and complex data types

- gold Open Access which fosters wider collaboration and increased citations

- maximum visibility for your research: over $100 \mathrm{M}$ website views per year

At $\mathrm{BMC}$, research is always in progress.

Learn more biomedcentral.com/submissions 